\title{
The Safe Thickness of Top Plate in the Process of the Underground Excavation Transferred to Opencast Excavation
}

\author{
Shiguo Sun ${ }^{1}$ Weidong Liu $^{2}$ Yujuan Zhang $^{3}$ \\ ${ }^{1}$ School of Civil Engineering,North China University of Technology, Beijing 100144, China \\ ${ }^{2}$ School of Civil Engineering,North China University of Technology, Beijing 100144, China \\ ${ }^{3}$ School of Civil Engineering,North China University of Technology, Beijing 100144, China \\ assg59@tom.com, ${ }^{\text {b4 } 403603959 @ q q . c o m}$
}

Keywords: Mining underground transferred to open pit operation.Mined-out area.The critical value.The safe thickness of top plate.Finite difference.

Abstract.Zijinshan gold mine once to mining local underground copper resources, result in the mined-out area which elevation from $460 \mathrm{~m}$ to $570 \mathrm{~m}$, the upper pit continue mining down the deep,one of the main problems in the safety production is that the large-scale mining equipment work whether fall into the mined-out area, it need to determine the problems of safe thickness of roof and reasonable value; First use six theoretical analysis methods, respectively was studied and calculating the safety thickness, then using finite difference software FLAC 3D are simulated on a 1-1 section, by comparing and comprehensive research, found that using numerical simulation method to get the calculation result is far above the theoretical calculation results. In the final analysis, determine the safe thickness of roof, which provide the decision basis for safety production.

\section{Introduction}

In recent years, the mining market increasingly active, mining developed mature, with the production become mechanization and scale. in order to achieve better benefit, more underground excavation transferred to opencast excavation ${ }^{[1]}$. According to some reference material, underground excavation transferred to opencast excavation can significantly improve the mine production capacity, realizing the economies of scale become maximization ${ }^{[2]}$. As the underground mine excavation transferred to opencast excavation,large changes have taken place of production in terms of environment and engineering structure at the same time,we will found some safe hidden trouble,which had not appear before.It's not good for mine safety in production, and even cause harm, not conducive to the steady development of mines ${ }^{[3-5]}$.

After the underground excavation transferred to opencast excavation,the safety of thickness of top plate, influenced whether the mine can be excavated. When the thickness of top plate is less than safety numerical,it may causes hazards such as collapse, so in front of the opencast excavation, we must determine the critical safety thickness of top plate to make sure that the production continuous safety ${ }^{[7-8]}$.

\section{General Situation Of Engineering Geological}

Zijin Gold and copper mine is in Shanghang county of Fujian province, Roughly purple mountain volcanic institutions。The mining area terrain is given priority with low mountain granite, it is the hill country of the southern section of Wuyi mountains east, Mining area is located in the southern section of the mountain, The Zijin mountain peak height $+1138 \mathrm{~m}$ above sea level, the lowest Mining area of south and northwest elevation $+300 \mathrm{~m}$, the elevation of most terrain near the deposit above +500 $\mathrm{m}$, the elevation of mining area minimum base level of erosion $+188 \mathrm{~m}$, the biggest height difference 
is $950 \mathrm{~m}^{[9]}$.

As the gold copper joint development project implementation, There are a large number of low grade ore body is difficult to recycle, at the same time,the reserved pillar can not be recovery because the opencast excavation of gold ore,With the deepening of strip mining,the decreaseing of the thickness of top plate will influence the safety of the underground copper mining.

In order to improve the production capacity of mining, Comprehensive utilization of copper resources, decided to transferred underground excavation to opencast excavation. The data shows, the excavation of Zijin gold and copper has formed a large number of mined-out area in $+460 \mathrm{~m}-570 \mathrm{~m}$ area,the average span mined-out area is $25 \mathrm{~m}$, According to the strip mining design scheme, Each of the open-pit mining steps $12 \mathrm{~m}$ high, Bottom elevation $+652 \mathrm{~m} \mathrm{now}^{[11]}$.

\section{The theoretical calculation method of the safe thickness of top plate}

Thick cross ratio method This article take the safety coefficient $\mathrm{K}=1.3$, Computation formula is as follows:

$$
H / K W \geq 0.5
$$

(H-The safety thickness of top plate, m; W- Gob span, m; K- Safety factor) .

Load transfer intersection line method Computation formula is as follows: $H=L_{n} / 2 \tan \beta$

( $\beta$ - According to load transfer line and the Angle between the roof center vertical line,the value is $35^{\circ}$; Ln- Gob span, m; H- The safety thickness of top plate,m.

Platts pressure arch method Computation formula is as follows:

$$
H=[\mathrm{b}+\mathrm{htan}(45-\varphi / 2)] / f
$$

(H- The height of pressure arch,m; $\varphi$ - Internal friction Angle of rock, ${ }^{\circ}$; b-The width of open stoping , $\mathrm{m}$; h-The maximum height open stoping, $\mathrm{m}$; $\mathrm{f}$ - The rock tensile strength。

Open stoping length-width ratio method According to size gob, the condition of roof rock and surrounding rock mass of cohesion, calculation points in two cases 。

1 ) When the lengths and widths of the mined-out area is greater than 2 :

$H_{\mathrm{n}}=\frac{L_{\mathrm{n}}}{8} \times \frac{\gamma L_{\mathrm{n}}+\sqrt{\gamma^{2} L_{\mathrm{n}}^{2}+16 \sigma\left(P+P_{1}\right)}}{\sigma}$

$P=\frac{\gamma H\left(K_{c}+K_{n}\right)}{K_{p}} \times K_{g}$

2) When the lengths and widths of the mined-out area is less than 2 :

$M_{\mathrm{x}}=$ Bending moment coefficient $\times \mathrm{pl}_{\mathrm{x}}^{2}$

$\sigma=\frac{M_{x}}{\frac{1}{12} b h^{2}}$

(5) Structural mechanics method of beam theory Computation formula is as follows:

$$
H=0.251_{n} \frac{y l_{n}+\sqrt{\left(y l_{n}\right)^{2}+8 b q \sigma_{a}}}{b \sigma_{a}}
$$




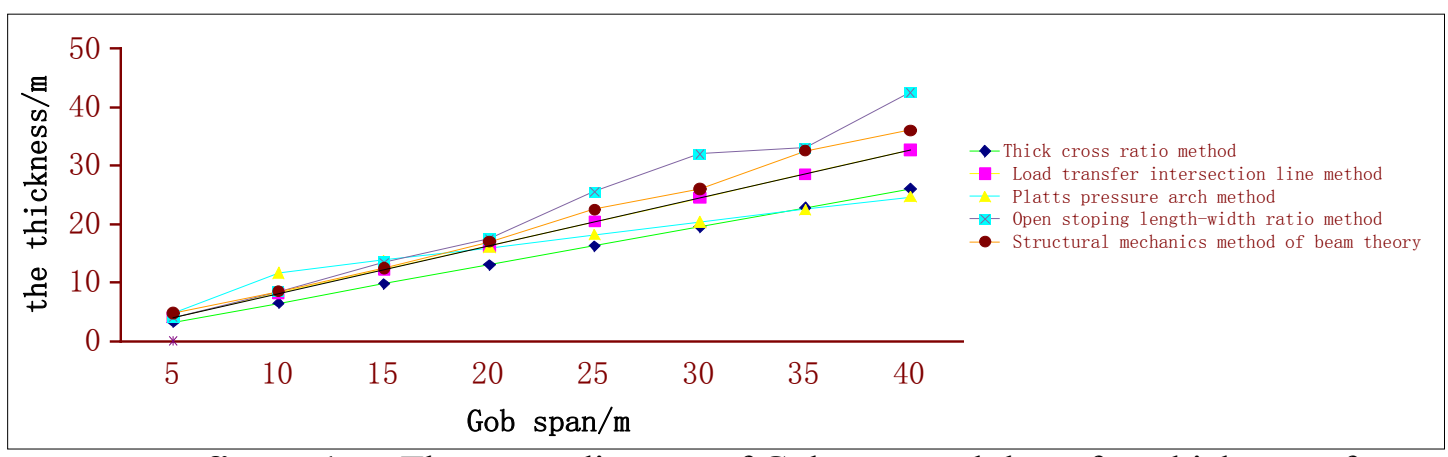

figure 1 The curve diagram of Gob span and the safety thickness of top plate

In this project, The average span mined-out area is $25 \mathrm{~m}$, Calculations to the safety thickness of top plate is:

Table1 The safety thickness of top plate from different calculation

\begin{tabular}{cc}
\hline Calculation method & The safety thickness of top plate $(\mathrm{m})$ \\
\hline Thick cross ratio method & 16.25 \\
Load transfer intersection line method & 17.85 \\
Platts pressure arch method & 19.9 \\
Open stoping length-width ratio method & 24.5 \\
Structural mechanics method of beam & 21.67 \\
theory & \\
\hline
\end{tabular}

The gob span is $25 \mathrm{~m}$, Calculate the average is $18.94 \mathrm{~m}$ 。

\section{The numerical simulation of goaf safety roof thickness}

Refer to engineering geological data, Open-pit mining steps is $12 \mathrm{~m}$, To establish the numerical model that the thickness is $92 \mathrm{~m}, 80 \mathrm{~m}, 68 \mathrm{~m}, 56 \mathrm{~m}, 44 \mathrm{~m}$, Determine a range of critical safety thickness of roof, By simulating the shear stress of the plastic zone map, To determine the critical safety thickness of top plate in a certain range.

\begin{tabular}{|c|c|c|c|c|c|c|c|c|c|}
\hline Name & $\begin{array}{l}\text { The rock } \\
\text { group }\end{array}$ & $\begin{array}{c}\gamma(\mathrm{K} \\
\mathrm{N} / \mathrm{m} \\
3 \\
3\end{array}$ & $\begin{array}{l}\mathrm{C}(\mathrm{M} \\
\text { pa) }\end{array}$ & $\varphi\left({ }^{\circ}\right)$ & $\begin{array}{l}\text { E } \\
\text { (Gpa } \\
\text { ) }\end{array}$ & $\mu$ & $\begin{array}{l}\mathrm{K} \\
\text { (Gp } \\
\text { a) }\end{array}$ & G (Gpa) & $\begin{array}{c}\sigma \mathrm{t}(\mathrm{M} \\
\mathrm{pa})\end{array}$ \\
\hline $\begin{array}{l}\text { In the fine grained } \\
\text { granite }\end{array}$ & I 1 & 29.4 & 0.7 & 39 & 38.5 & 0.31 & 33.77 & 14.69 & 4.62 \\
\hline $\begin{array}{l}\text { In the fine grained } \\
\text { granite }\end{array}$ & I 2 & 27.9 & 0.65 & 38.08 & 38.6 & 0.31 & 33.86 & 14.73 & 3.86 \\
\hline $\begin{array}{l}\text { In the fine grained } \\
\text { granite }\end{array}$ & II 1 & 26.5 & 0.6 & 38 & 37.5 & 0.3 & 31.25 & 14.42 & 3.1 \\
\hline $\begin{array}{l}\text { In the fine grained } \\
\text { granite }\end{array}$ & II 2 & 25.4 & 0.35 & 35.5 & 37 & 0.33 & 36.27 & 13.91 & 2.64 \\
\hline $\begin{array}{l}\text { In the fine grained } \\
\text { granite }\end{array}$ & III & 26.2 & 0.15 & 33.04 & 27.3 & 0.23 & 16.85 & 11.1 & 1.85 \\
\hline
\end{tabular}




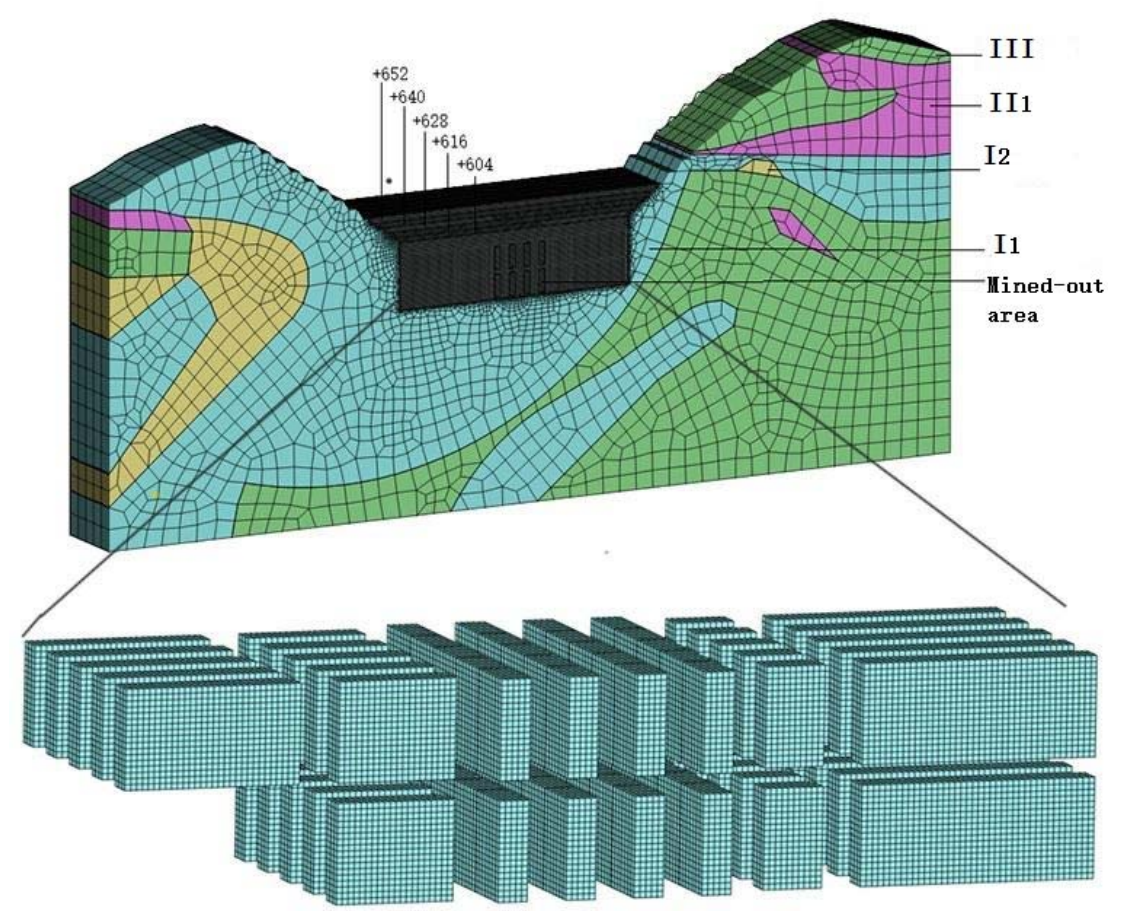

Figure 3 The numerical model

According to the strength subtraction of the safety thickness of top plate, On the analysis of the stability of the top plate,There are two kinds of general determine whether the structure damage.One approach is to adopt structural convergence as the basis of determining whether or not,Use Moore coulomb criterion whether the calculation is convergence under the FLAC $3 \mathrm{~d}$ software.Another method is at the end of the calculation, whether the plastic zone is through the top plate,Its physical meaning is clear.

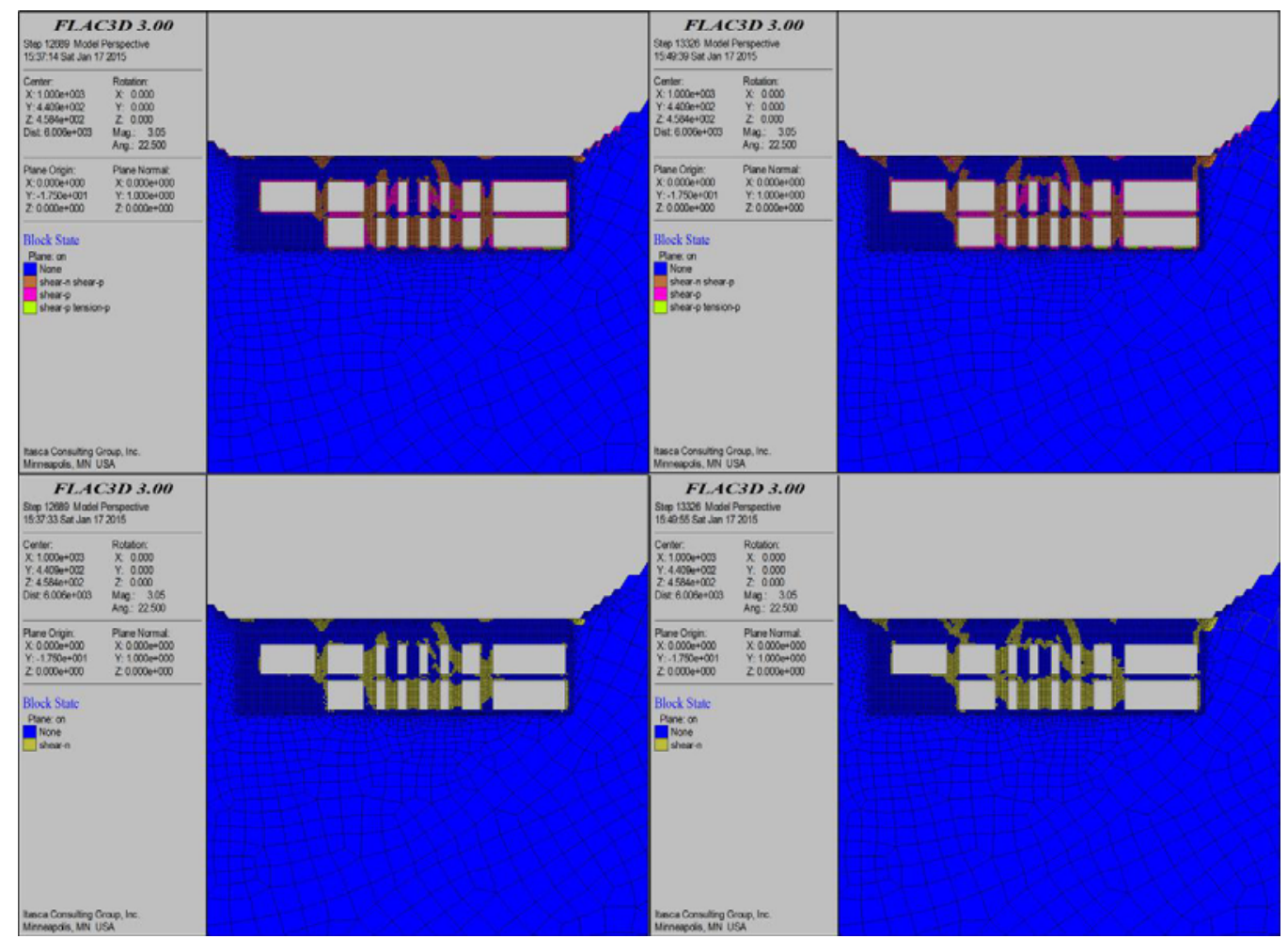

Figure 4 the thickness of top plate is $45 \mathrm{~m} 、 44 \mathrm{~m}$ 
Through the numerical simulation, receive the plastic zone map, when the thickness of top plate is $45 \mathrm{~m}$, the plastic zone is not through the top plate.when the thickness of top plate is $44 \mathrm{~m}$, the plastic zone is through the top plate,it means mined-out area and the surface have formed a potential sliding channel, The model is shear failure, it may make the top plate collapse.So we can determine the thickness of top plate is $45 \mathrm{~m}$ 。

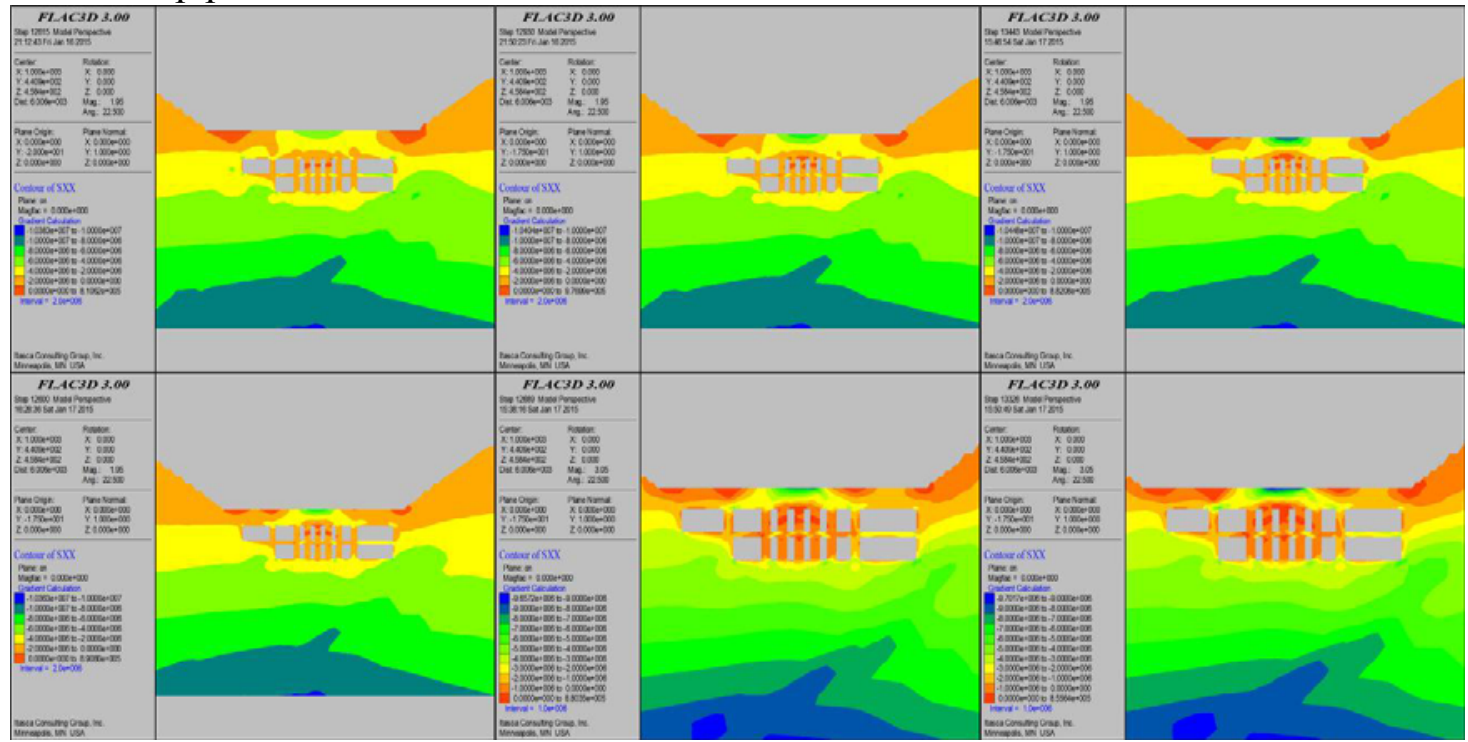

Figure 5 the horizontal stress nephogram when the thickness of top plate is $92 \mathrm{~m} 、 80 \mathrm{~m} 、 68 \mathrm{~m}$ 、 $56 \mathrm{~m} 、 45 \mathrm{~m} 、 44 \mathrm{~m}$ (unit: N)

As is shown in the horizontal stress nephogram,the top plate under the weight of the overburden strata will produce bend.Take the mined-out area at the top of the unit as the research object,from the surface to the top plate,the horizontal stress of rock gradually transformed the compressive stress to tensile stress, And with the thickness of top plate decreases, tensile stress area become smaller and smaller, Compressive stress area become more bigger. This is because with the open-pit mining boundary line become lower, The slope on both sides of the mined-out area is more and more steep, the open pit bottom extrusion bigger, to offset part of the gob roof tensile stress produced by weight. And slope foot due to stress concentration, suffered a large tensile stress, When the thickness of the top plate get thinner, tensile region in the middle of the top plate become bigger, produce tensile damage, the ability of damage of the rock mass at both ends of the top plate become lower, generate shear failure.

\section{Summary}

Zijin gold mine of underground mining form a large number of mined-out area, and formed a serious threat to the open stope production safety, using the theory and numerical simulation method to calculate the limit of the goaf roof safety thickness, get the theoretical calculation value of $19 \mathrm{~m}$, the results of numerical simulation for $45 \mathrm{~m}$. The numerical simulation results are far greater than the theoretical calculation results.

Although using theoretical calculation method can calculate the limit of a single goaf safety roof thickness, But in actual engineering, In the process of underground mining tends to form a series of underground mined-out area, And the adjacent goaf between each other will influence each other, This also affect the safety of the gob top plate thickness, Using numerical simulation method, using finite difference software FLAC 3d, set up a numerical model, considering various factors and the influence of adjacent goaf, Calculate the mined-out area the safe thickness of top plate of the critical value, it is benefit for the safe production of the opencast stope. 


\section{Acknowledgements}

The first auther: Sun Shiguo(1959- ),male,Postdoctoral.The professor of the northern industrial university majoring in civil engineering construction engineering college level discipline responsibility, doctoral supercisor.Mine safety and the northern industrial university institute of geotechnical engineering.

Fund project: This research has been funded by the National Natural Science Foundationg of China(No.411722250),National five-year science and technology support project(2012BAK09B06), The innovative team project of Beijing(IDHT20140501), The scientific research base construcction,scientific researh innovation platform,scientific research and special-impact pressure build of microseismic monitoring and early warning system(XN083) and new type of anchor reinforcement technique field test research and graduate student ability trainning(XN107).

\section{References}

[1] Sun Shiguo,Cai Meifeng.A method for evaluation of slope rock-mass stibility under the combined action pit and underground mining[J].Journal of Engineering Geology,1998, 6(4):312-318.

[2] Liu Xiaobo,Peug Jianyu. Goaf Roof Failure Mechanism and its Security Thickness[J].Metal Mine, 2012 (11): 5-9.

[3]Sun Shiguo,Cai Meifeng, Wang Sijing.Effect of combined underground and open pit mining and deformation mechanism of slope[J].Chinese Journal of Rock Mechanics and Engineering,1999,18(5): 563-566.

[4] Zeng Zhuangli, Jiang Xueliang, Liu Ziyou.Analysis of underground cavern's roof safety thickness with FLAC 3D.Sichuan Building materials, 2010 (3): 51-53.

[5] He Zhongming,Peng Zhenbin,Cao Ping.Numerical analysis for roof stability of double gob area after excavation by FLAC 3D[J].Journal of Central South University(Since and Technology),2009(4): 1066-1071.

[6] Itasca Consulting Group Inc. 3DEC Three-dimensional Distinct Element Code Version 3.0 User's Manual[R].Itasca Consulting Group Inc.1988.

[7] He Wei, Ye Zhenhua. Predictive Research on the Safety Thickness of Roof in Mine Excavation based on Dichotomy Optimization Theory[J].Morden Mining, 2011 (1): 19-21.

[8] Li Changhong,Zhang Yong,Cai Meifeng,ental.FEM-based inversion analysis of in-situ stress field of Zijinshan Gold-copper Mining Area[J].Metal Mine,2008(7):1-18.

[9] Zhou Xiaochao, Hou Kepeng. Analysis of roof safety thickness of the underground goaf based on improved beam model.Mining \& Metallurgy, 2014 (1): 21-25

[10] Lin Hang,Cao Ping,Li Jiangteng. The thickness reductionmethod in forecasting the critical safety roof thickness of gob area. Journal of China Coal Society.

[11] Liu Xianhua.Technical research of goaf disposal in Zijinshan Gold Mine[J].Nonferrous Mines,2002,31(1):21-43. 